\title{
Interfacial catalysis in biphasic carboxylic acid esterification with a nickel-based metallosurfactant
}

Andreas Toth*, Silke Schnedl, Daniela Painer, Matthäus Siebenhofer and Susanne Lux

Graz University of Technology, Institute of Chemical Engineering and Environmental

Technology, NAWI Graz Central Lab Biobased Products, Inffeldgasse 25c/III, 8010 Graz

Austria

*E-mail: andreas.toth@,tugraz.at; Phone: +43 3168737460

Number of pages: 4

Number of tables: 1

Number of figures: 2 
Table S1: Investigated metal ions, solvent mixtures and reasons for exclusion

\begin{tabular}{|c|c|c|c|}
\hline metal ion & metal salt & solvent mixtures & reasons for exclusion \\
\hline $\mathrm{Fe}(\mathrm{II})$ & $\mathrm{FeCl}_{2} \cdot 4 \mathrm{H}_{2} \mathrm{O}$ & $\begin{array}{c}n \text {-undecane } \\
n \text {-undecane/Cyanex }{ }^{\circledR} 923 \\
n \text {-undecane/DEHPA } \\
n \text {-undecane/1-octanol }\end{array}$ & $\begin{array}{ll}\text { - } & \text { negligible catalytic activity } \\
\text { - } & \begin{array}{l}\text { instability of complex, due to } \\
\text { oxidation of Fe(II) to Fe(III) }\end{array} \\
\text { - } & \begin{array}{l}\text { preferably water soluble } \\
\text { metallosurfactants }\end{array}\end{array}$ \\
\hline $\mathrm{Fe}(\mathrm{III})$ & $\mathrm{FeCl}_{3} \cdot 6 \mathrm{H}_{2} \mathrm{O}$ & $\begin{array}{c}n \text {-undecane } \\
n \text {-undecane/Cyanex }{ }^{\circledR} 923 \\
\text { n-undecane/DEHPA } \\
\text { n-undecane/1-octanol }\end{array}$ & 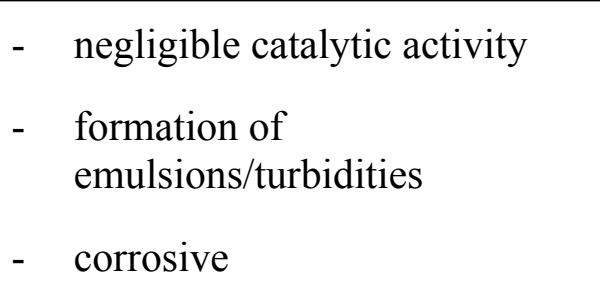 \\
\hline $\mathrm{Ni}(\mathrm{II})$ & $\begin{array}{c}\mathrm{NiSO}_{4} \cdot 6 \mathrm{H}_{2} \mathrm{O} \\
\mathrm{Ni}(\mathrm{OH})_{2}\end{array}$ & $\begin{array}{c}n \text {-undecane } \\
n \text {-undecane/Cyanex }{ }^{\circledR} 923 \\
n \text {-undecane/DEHPA }\end{array}$ & $\begin{array}{ll}\text { - } & \text { water solubility of } \\
\text { metallosurfactants from } \mathrm{NiSO}_{4}\end{array}$ \\
\hline
\end{tabular}




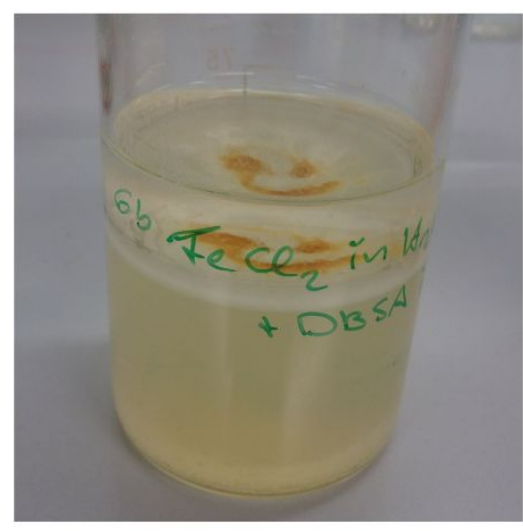

a) oxidation of $\mathrm{Fe}(\mathrm{II})$ to $\mathrm{Fe}(\mathrm{III})$

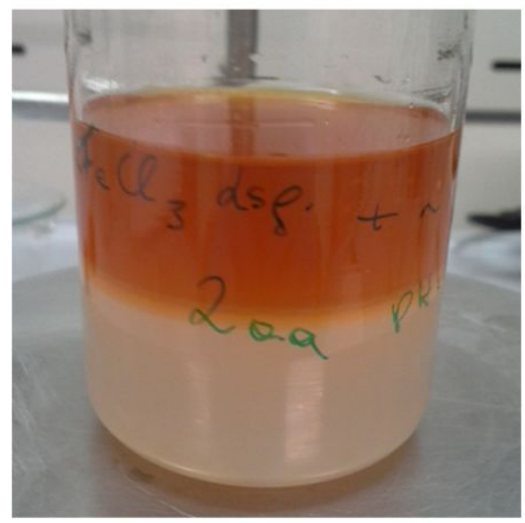

c) low solubility of $\mathrm{FeCl}_{3}$ with emulsification

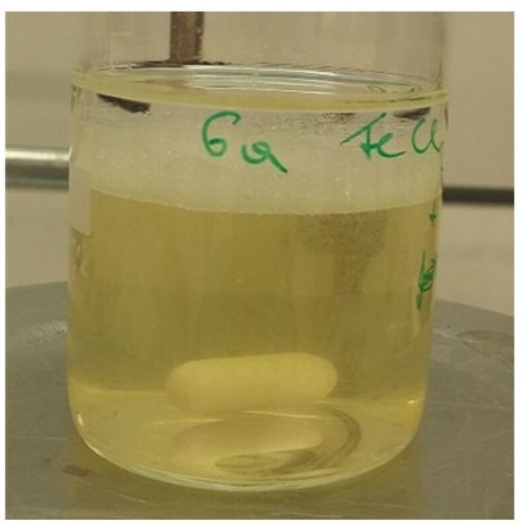

b) high water solubility of $\mathrm{Fe}(\mathrm{II})$

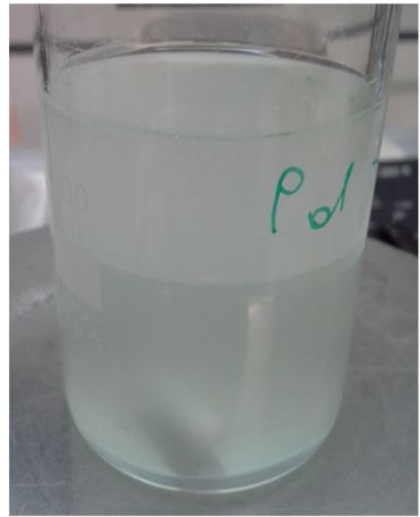

d) low solubility of $\mathrm{NiSO}_{4}$ with emulsification

Figure S1: Metallosurfactant solution behavior in biphasic environment: a) $\mathrm{Fe}(\mathrm{II})$ oxidizes over time to $\mathrm{Fe}(\mathrm{III})$ visible as rust-colored precipitate; b) Fe(II) metallosurfactants exhibit high water solubility, undesired for the investigated application; c) Fe(III) metallosurfactants tend to form a fine precipitate with low solubility in solvent phase and cause emulsification/turbidity at the interface and the aqueous phase; d) metallosurfactants prepared from $\mathrm{NiSO}_{4}$ show unfavorable solubility in both phases. 


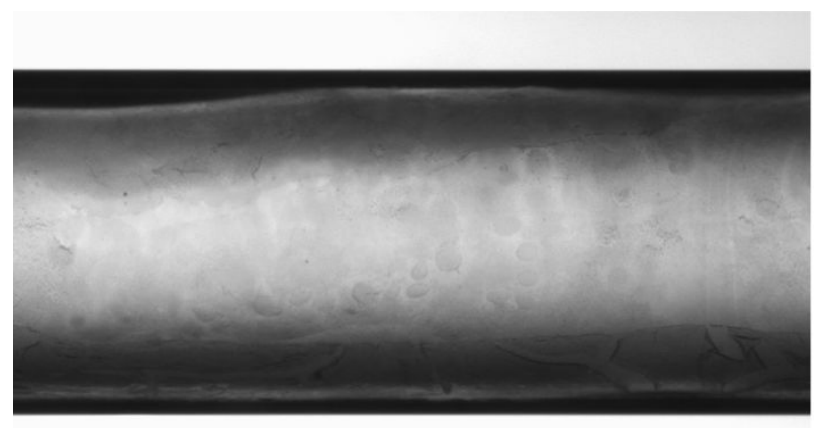

a) complete emulsification of 4-DBSA/solvent mixture

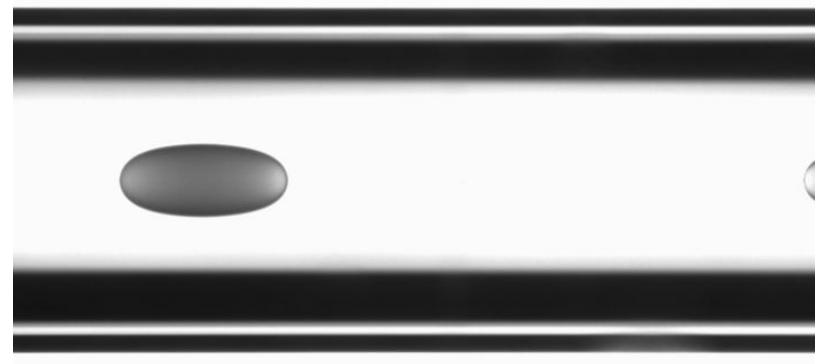

b) formation of drops with internal emulsification

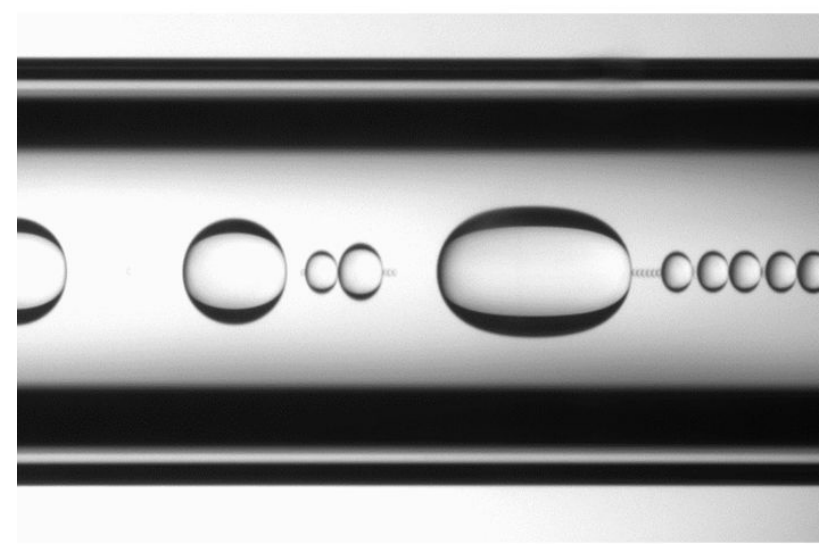

c) well shaped, stable drops without emulsification

Figure S2: Pictures of drops in the measurement capillary of the spinning drop video tensiometer with deionized water as continuous phase: a) 4-dodecylbenzenesulfonic acid (4-DBSA) lowers the interfacial tension by an order of magnitude where measurement is impossible due to complete emulsification; b) unrinsed $\mathrm{Ni}(\mathrm{DBSA})_{2} / 1$-octanol solution forms well shaped drops, but residual 4-DBSA induces internal emulsification preventing reproducible measurement; c) rinsed $\mathrm{Ni}(\mathrm{DBSA})_{2} / 1$-octanol solution forms well shaped, stable drops without emulsification 